\title{
Toward a National Agenda in Materials Science and Engineering
}

Publication of the comprehensive report, Materials Science and Engineering for the 1990s: Maintaining Competitiveness in the Age of Materials, has proved to be a watershed event in the materials science and engineering (MS\&E) community. Completed in 1989, this report has fundamentally changed the way we look at MS\&E. The consequences are far reaching: the recognition of MS\&E as a coherent field, the emergence of unity in the MS\&E community at the grassroots level, and the acceptance of materials as a national priority. The architects of this report and the report's subsequent national exposure have created a compelling case for a national agenda in MS\&E.

Coherence and unity in MS\&E have been the subject of much discussion in recent years. The MS\&E report has articulated these issues and placed into motion a national dialogue among practitioners of the discipline which has in effect demonstrated this coherence and unity, producing for the first time a strong national voice for the materials community. Make no doubt about it: the political stock of the materials community has changed.

The MS\&E study, chaired by Praveen Chaudhari and Merton Flemings, involved the work of hundreds of scientists and engineers. Following the report's publication, the study was discussed at numerous public forums (including the 1989 Fall Meeting of the Materials Research Society). These discussions produced a consensus that the study's key findings should be acted upon, and that regional meetings should be held in the MS\&E community to involve working scientists and engineers in the process of further developing and implementing the recommendations.

Four regional meetings were held in 1990 involving more than 400 scientists and engineers from industry, academia, and government laboratories. Although each regional meeting was organized independently, it is highly significant that many common recommendations were forwarded. The individual meeting reports

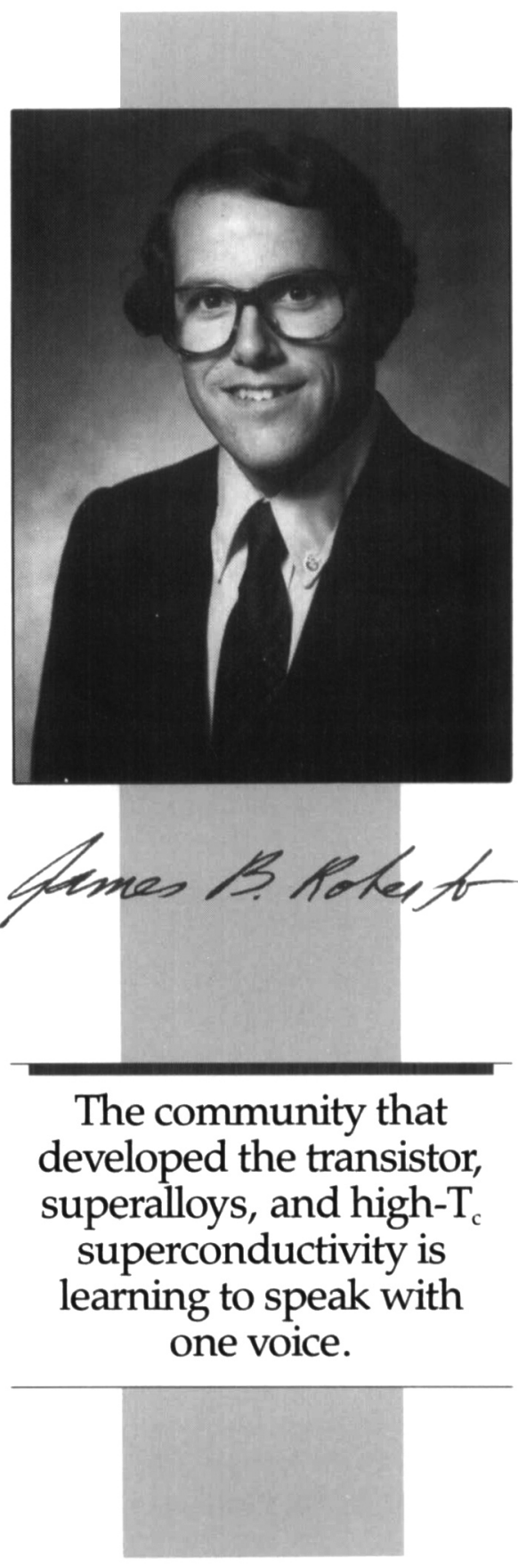

have now been assembled into a consensus document, A National Agenda in Materials Science and Engineering: Implementing the MSEE Report, which was presented to the Office of Science and Technology Policy (OSTP) and the federal agencies on January 25,1991 . This report was published by MRS in February and presented to the scientific community at the Solid State Sciences Committee Forum on February 27.

In summary, the consensus report recommends a strategic, goal-oriented planning process for MS\&E; increased industry, university, government laboratory cooperation; improvements in MS\&E curricula and instructional equipment; and new initiatives in MS\&E based on national planning and prioritization. The price tag: $\$ 1.25$ billion per year. I refer you to the article on the consensus report in this issue for the details.

The point of this message is not the specific recommendations of the report. Realistically speaking, these are a starting position for negotiations within the constraints of the political process. The message is that the MS\&E community is finally at the table. The community that developed the transistor, superalloys, and hightemperature superconductivity is learning to speak with one voice.

I am proud of the strong role that MRS has played in promoting this development. The pioneering format of our technical meetings has done much to encourage coherence and unity in MS\&E. I am also proud of the strong role that MRS has played in the unfolding of these historic events. From distinguished representation on the MS\&E study to a significant role in the regional and national consensus meetings, MRS people have been very visible and effective in this process. As we move toward a national agenda in MS\&E, I applaud those who have led the way and encourage each of you to contribute to this critical initiative for our field and the nation.

Jim Roberto 


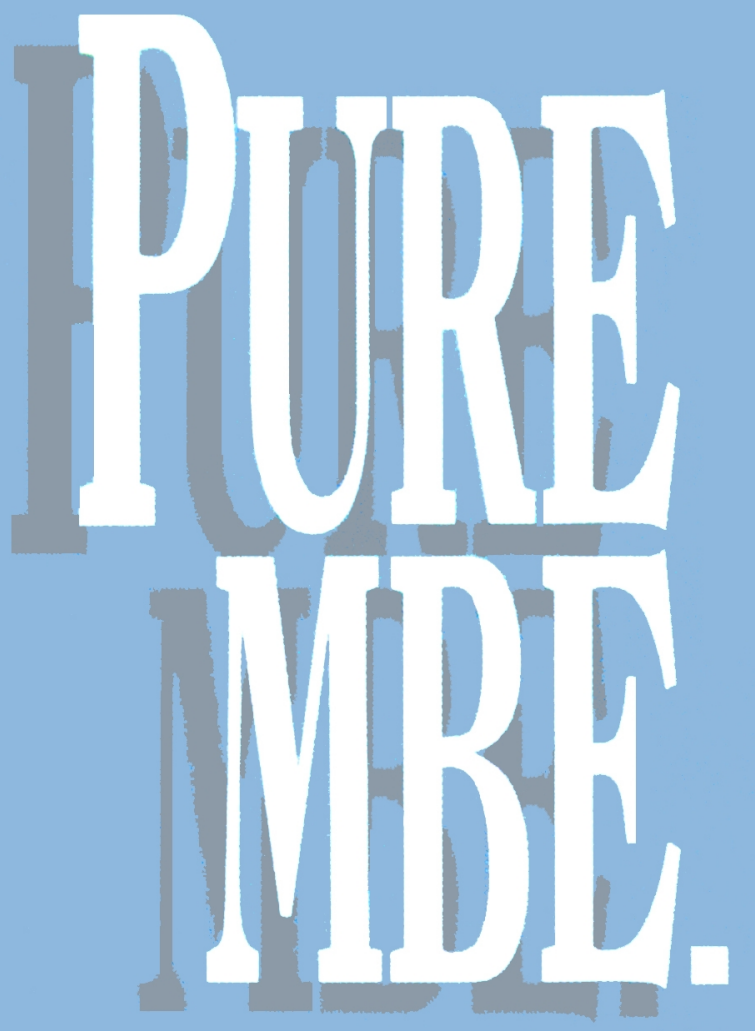

\section{EPI MBE Components}

- Valved Cracking Cells

- Standard Cracking Cells

- Dual Filament Cells

- Modified Filament Cells

- High Temperature Cells

Low Temperature Cells

Dopant Sources

- Filament Evaporators

- Gas Sources

\section{EPI... The Source for MBE}

For more information, please call us at 612/224-1140 or send your facsimile transmission to 612/224-0266

261 East Fifth Street $\square$ St. Paul, MN 55101 USA

Please visit Booth No. 418 at the MAS Show in Anaheim, CA, April 30-May 2, 1991.

U.K.: Caburn UHV, 1 Castle Ditch Lane. Lewes, East Sussex BN7 1YJ, U.K. Telephone 0273480081 Fax 0273480545

Cirele No. 8 on Reader Service Card.
France: Sofrasil SA. Centre Affaire Paris-Nord. Immeuble "Le Bonaparte", 93153 Blanc Mesnil. France Telephone 0145910008 Fax 0148652193
The EPI Valved Cracker, for As, $P$ and Se.

The first solid source cracker to include mechanical control over flux density, providing unrivaled precision, ease-of-use and control. 


\section{KEY APPLICATIONS IN 1 POWERFUL, COMPACT SYSTEM}

\section{$\begin{array}{llllllllll}A & N & N & O & \text { U } & \text { N } & \text { C } & \text { I } & \text { N } & \text { G }\end{array}$}

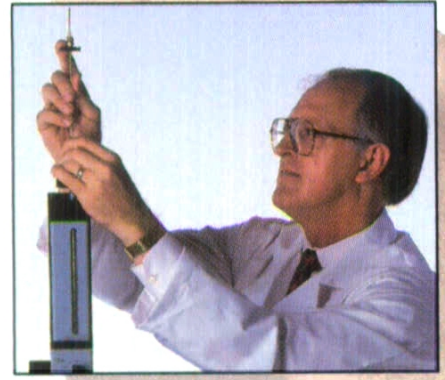

Proven SQUID

Technology

The MPMS 2 is a versatile member of our industry-leading MPMS family. Which means proven hardware, plus a suite of software tools that make operation and development of custom applications quick, easy and efficient.

\section{Enhanced SQUID} Capabilities

The MPMS2 also introduces new levels of control and sensitivity to push the limits of previously available capability. For example, AC Drive fields of 1 milliGauss to 1 Gauss with frequencies of $5 \mathrm{~Hz}$ to $1 \mathrm{KHz}$. For $\mathrm{AC}$ and DC measurements, the remnant field can be zeroed to 2 milliGauss. And the applied DC field can be controlled from 50 milliGauss to 10 KiloGauss.

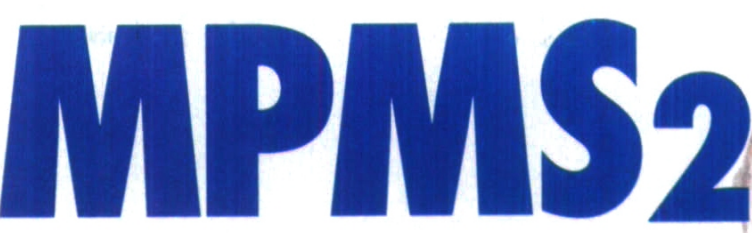

The Complete Magnetic Research Laboratory

Quantum Design's MPMS2

(Magnetic Property Measurement System 2)

creates a whole new concept, the laboratory work station.

DC Magnetization

AC Susceptibility

Low Field Option

Hall Effect

Resistivity

\section{And More}

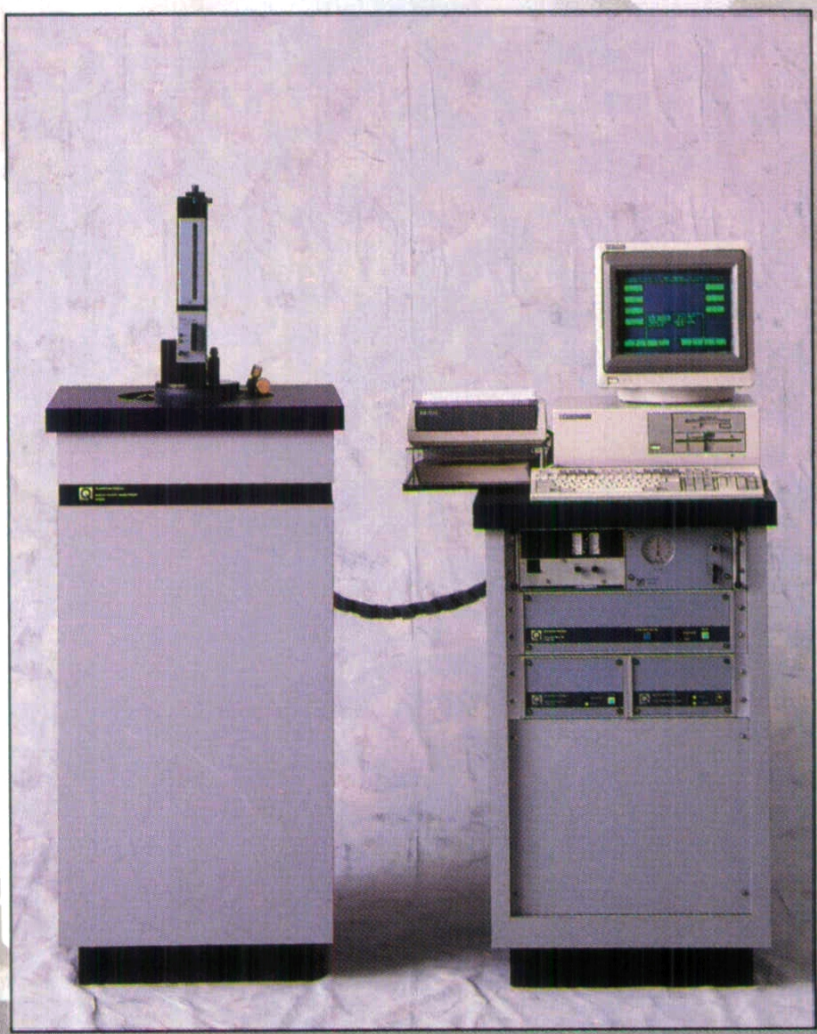

Quantum Design's MPMS2 offers 5 key applications in 1 powerful, compact system.
Saves You More Than Money

With the MPMS2

you can meet your total magnetic materials research needs with one compact system. Which simplifies training and use, conserves floor space and holds acquisition and operating costs to a minimum. So you save at every step from "day one".

\section{See What The MPMS2} Can Do For You

Contact us or your nearest Quantum Design Representative today for details on the MPMS 2 - - the complete magnetic research laboratory for 5 key applications in 1 powerful, compact system.

\section{QUANTUM DESIGN}

Delivering Advanced Technology Today.

\section{Quantum Design}

11578 Sorrento Valley Road Suite 30, San Diego, California USA 92121-1311

Call Toll-Free 800-289-6996

Phone 619-481-4400

Fax $619-481-7410$

\begin{tabular}{|c|c|c|c|c|c|}
\hline AUSTRALIA & EUROPE & INDIA & JAPAN & KOREA & TAIWAN \\
\hline Domo-Technica Pty. Ltd. & S.H.E. GmbH & V.S. Scientific Instrument Agency & Niki Gloss Co. Ltd. & Hanmac Corp. & Scienchem Corp. \\
\hline Pbone: (02) 85-7761 & Pbone: (0241) 15-50-37 & Pbone: (11) 644-7577 & Pbone: (03) $3456-4700$ & Pbone: (02) $553-7441$ & Pbone: (02) 641-3924 \\
\hline Fax: $(02) 858-4212$ & Fax: $(0241) 15-69-12$ & $\operatorname{Fax}:(11) 642-5540$ & $\operatorname{Fax}(03) 3456-3423$ & Fax: $(02) 556-6816$ & Fax: (02) 641-0790 \\
\hline
\end{tabular}




\section{Rapid Thermal Processing - LPCVD}

The new modular RX Series, lets you configure precisely the system you need to perform or develop virtually any application demanding a thermal process - from the most basic annealing process to the most complex LPCVD environment. Ask for the price, you will be surprised!

\section{The RX series for RTP.}

The $R X$ is a fully automated integrated processor featuring:

- Fast heating rates with ramp-up rates up to $400^{\circ} \mathrm{C} / \mathrm{sec}$ and fast cooling rate to get abrupt junctions with a unique cooling system.

- Temperature uniformity computer controlled in real time, with multizone furnace.

- Cleanliness with a quartz chamber designed for medium or high vacuum options with automatic vacuum cycles and pressure programming.

- Gas control/mixing.

- Unique graphics software. The environment is entirely computer controlled, including complete process data storage and retreival, hardware calibrations and maintenance.

\section{The RX series for LPCVD.}

With its many years of experience in Rapid Thermal Processing, AET Addax has developed proprietary features for LPCVD, and has addressed major concerns regarding the application of RTP to LPCVD:

- The ultra high vacuum (10-9 torr) quartz chamber offers an extremely clean environment to generate ultra pure films.

- The combination of a very small volume processing chamber and fast gas switching system produces a low memory effect for sharp transitions.

- The advanced cooling system provides "cold wall quartz" capabilities. A specfic module is available for installation on UHV stainless steel chambers.

- Removable chamber for cleaning or to avoid cross contamination between processes.

- Safety features with interlocks, leak tight double enclosure for toxic gases, automatic reset procedures.

Please visit Booth No. 416 at the MRS Show in Anaheim, CA, April 30-May 2, 1991.
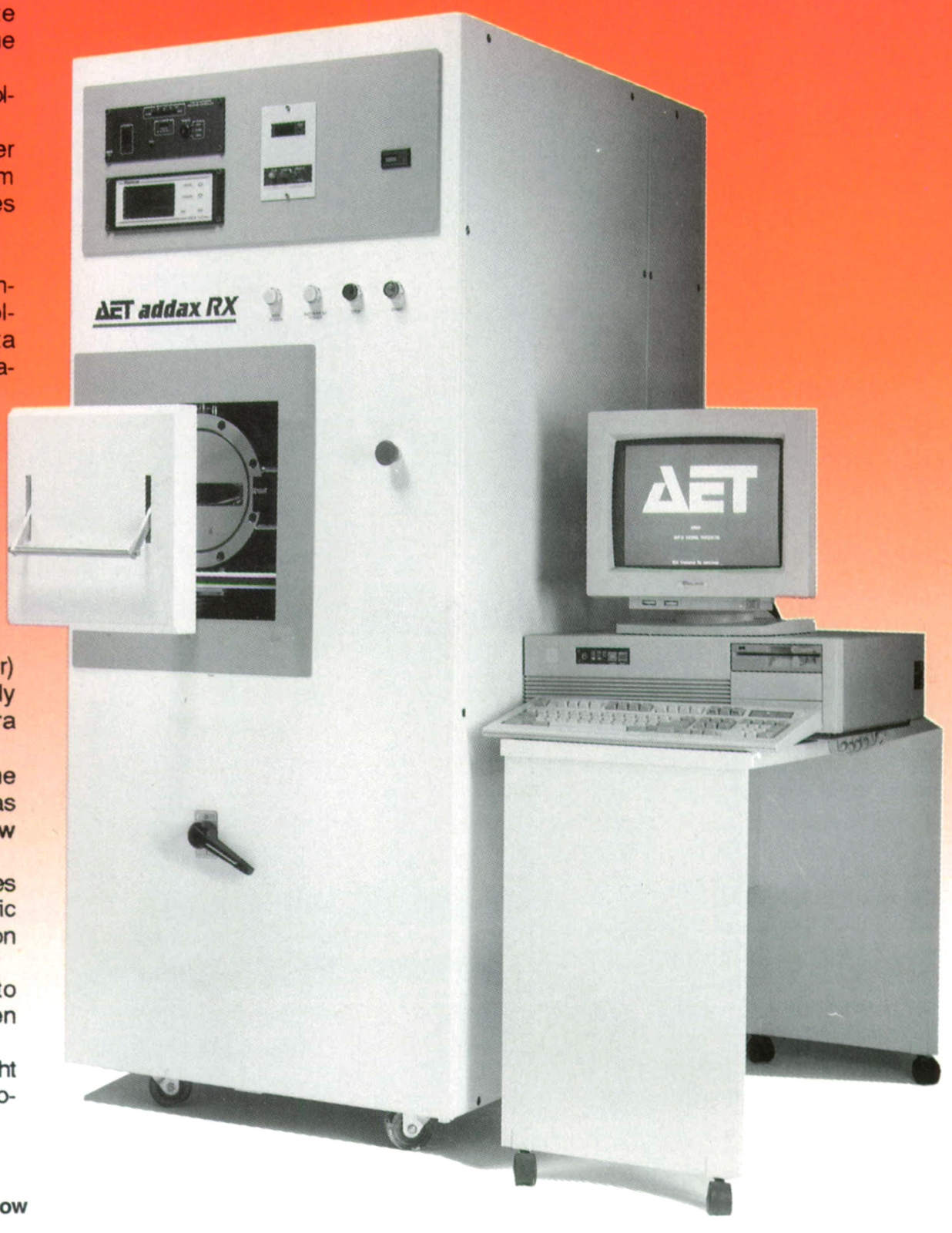

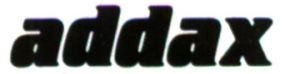

SEMICONDUCTOR EQUIPMENT

DIVISION
743 Ames Avenue, MILPITAS, CA 95035. Tel: (408) 263-5464. Fax: (408) 263-9825

Circle No. 10 on Reader Service Card. 